\title{
The First Case of Reactive Arthritis Associated with SARS-CoV-2-Infection in A 4-Year Old Child
}

\section{Stephanie Gabriele Werner ( $\nabla$ dr.werner@rhio.de )}

RHIO (Rheumatology, Immunology, Osteology) Duessledorf https://orcid.org/0000-0002-6566-3740

Hans-Eckhard Langer

RHIO (Rheumatology, Immunology, Osteology) Duesseldorf

\section{Case Report}

Keywords: COVID-19, SARS-CoV2, reactive arthritis, juvenile arthritis, lyme disease

Posted Date: November 18th, 2020

DOl: https://doi.org/10.21203/rs.3.rs-106976/v1

License: (9) (1) This work is licensed under a Creative Commons Attribution 4.0 International License. Read Full License 


\section{Abstract}

Background: The novel coronavirus SARS-CoV-2 (severe acute respiratory syndrome coronavirus 2) and its associated disease COVID-19 (Corona Virus Disease 19) has become a worldwide pandemic since its first cases in December 2019 in Wuhan Province in China. In Germany the pandemic started in February 2020.

Case presentation: A 4 year old boy was presented and suffered from pain in the right hip. Arthrosonography demonstrated a significant effusion in the involved joint. The extended history revealed a slight but long lasting cold before. Serological findings were inconspicuous except for positive ELISA (Enzyme-linked Immuno Sorbent Assay) - test for SARS-CoV-2.

Conclusion: In conclusion we believe that we can report the first case of reactive arthritis associated with SARS-CoV-2 in children.

\section{Background}

The novel Coronavirus SARS-CoV-2 (severe acute respiratory syndrome coronavirus 2) and its associated disease COVID-19 (Corona Virus Disease 19) has become a worldwide pandemic since its first cases in December 2019 in Wuhan Province in China. In Germany the pandemic started in February 2020.

The first case of reactive arthritis associated with COVID-19 was reported in a 73-year old man from Turkey (1). To the best of our knowledge reactive arthritis due to a SARS-CoV-2-Infection has not been described in children yet.

\section{Case Presentation}

A 4 year old boy was presented in our outpatient clinic of rheumatology in the first week of May. The child suffered from pain in the right hip spreading to the right knee since one week. Clinical examination showed free movement of hip and knee but arthrosonography revealed a joint effusion in the right hip (Fig. 1). Other joints were not affected. Laboratory diagnostics did not show any signs of systemic inflammation or bacterial infections (c-reactive protein $0.0 \mathrm{mg} / \mathrm{dl}, 6.740$ leucocytes/ $\mathrm{ul}$ ).

While our leading differential diagnosis was coxitis fugax the diagnostic work-up included serological testing for Lyme disease, because the parents told us that the boy spend a plenty of time in the nature. Extended history revealed that he was affected by a slight but long lasting cold with persistent rhinitis and sore throat from the middle of March until the middle of April. The parents reported no fever but intermittent headache and subfebrile temperatures. Based on the pandemic situation we asked the family about typical of signs of COVID-19 or established disease in contacts. The rest of the family (parents, the 6 year old sibling and grandparents) were not affected by any signs or symptoms. No cases of COVID-19 were known in the play school. 
Since an infection with the novel virus could not be excluded, we completed the diagnostic with an ELISAtesting for SARS-CoV-2 (3). SARS-CoV-2 IgG (Immunglobuline G) ELISA was positive with a ratio of 1,00 (normal < 0.8) while SARS-CoV-2 IgA (Immunglobuline A) ELISA showed a relatively high titer but was rated as negative (ratio 0,64 , normal $<0.8$ ). A confirmatory test was performed 14 days later and established the diagnosis of an expired infection with SARS-CoV-2 (SARS-CoV-2 IgG ELISA: ratio 1,19; SARS-CoV-2 IgA ELISA: ratio 0,85; SARS-CoV-2 IgM (Immunglobuline M) ELISA: negative).

At a follow-up-visit 8 weeks later the boy was free of signs and symptoms of the previous coxitis. All articular joints were normal at clinical examination. The joint effusion could not be demonstrated by arthrosonography anymore (Fig. 2).

\section{Discussion}

In general children seem to be affected by SARS-CoV-2 less severe (2). Thus signs and symptoms are less distinct and more unspecific and are often similar to a slight cold. At the mentioned time of the pandemic in Germany, PCR-testing (Polymerase Chain Reaction) was reserved for severely infected patients. Thus, our patient with less signs and symptoms was not tested with PCR to confirm an infection with SARS-CoV-2. But the ELISA-testing was able to establish an expired infection even in the confirmation test 14 days later. The chronological order of the signs and symptoms and the lack of other cause confirmed our clinical diagnosis of a reactive arthritis associated with a SARS-CoV-2-Infection.

\section{Conclusion}

In conclusion we believe that we can report the first case of reactive arthritis associated with SARS-CoV-2Infection in children. Further case-reports are remaining to be seen.

\section{List Of Abbreviations}

SARS-CoV-2: severe acute respiratory syndrome coronavirus 2

COVID-19 : Corona Virus Disease 19

ELISA: Enzyme-linked Immuno Sorbent Assay

IgG: Immunglobulin G

IgA: Immunglobuline A

IgM: Immunglobuline M

PCR: Polymerase Chain Reaction

\section{Declarations}


Ethics approval and consent to participate: This manuscript fulfills the recommendations of the Declarations of Helsinki.

Consent for publication: We have an obtainded consent form by the parents of the reported child.

Availability of data and materials: The datasets of the presented case are available from the corresponding author on reasonable request

Competing interest: The authors SGW and HEL declare that they have no competing interests regarding this case report.

Funding: Not applicable.

Author's contributions: SGW and HEL were involved in examination, interpretation of the results and treatment of the mentioned patient in this case report. SGW and HEL drafted the manuscript. All authors read and approved the final manuscript.

Acknowledgements: Not applicable.

\section{References}

1. Saricaoglu EM, Hasanoglu I, Guner R. The first reactive arthritis case associated with COVID-19. J Med Virol. 2020 Jul 19 [Epub ahead of print].

2. Licciardi F, Giani T, Baldini L, et al. COVID-19 and what pediatric rheumatologists should know: a review from a highly affected country. Pediatr Rheumatol. 2020;18:35.

3. Anti-CoV-2 IgA-ELISA. IgG-. ELISA, IgM- ELISA, EUROIMMUN AG.

\section{Figures}




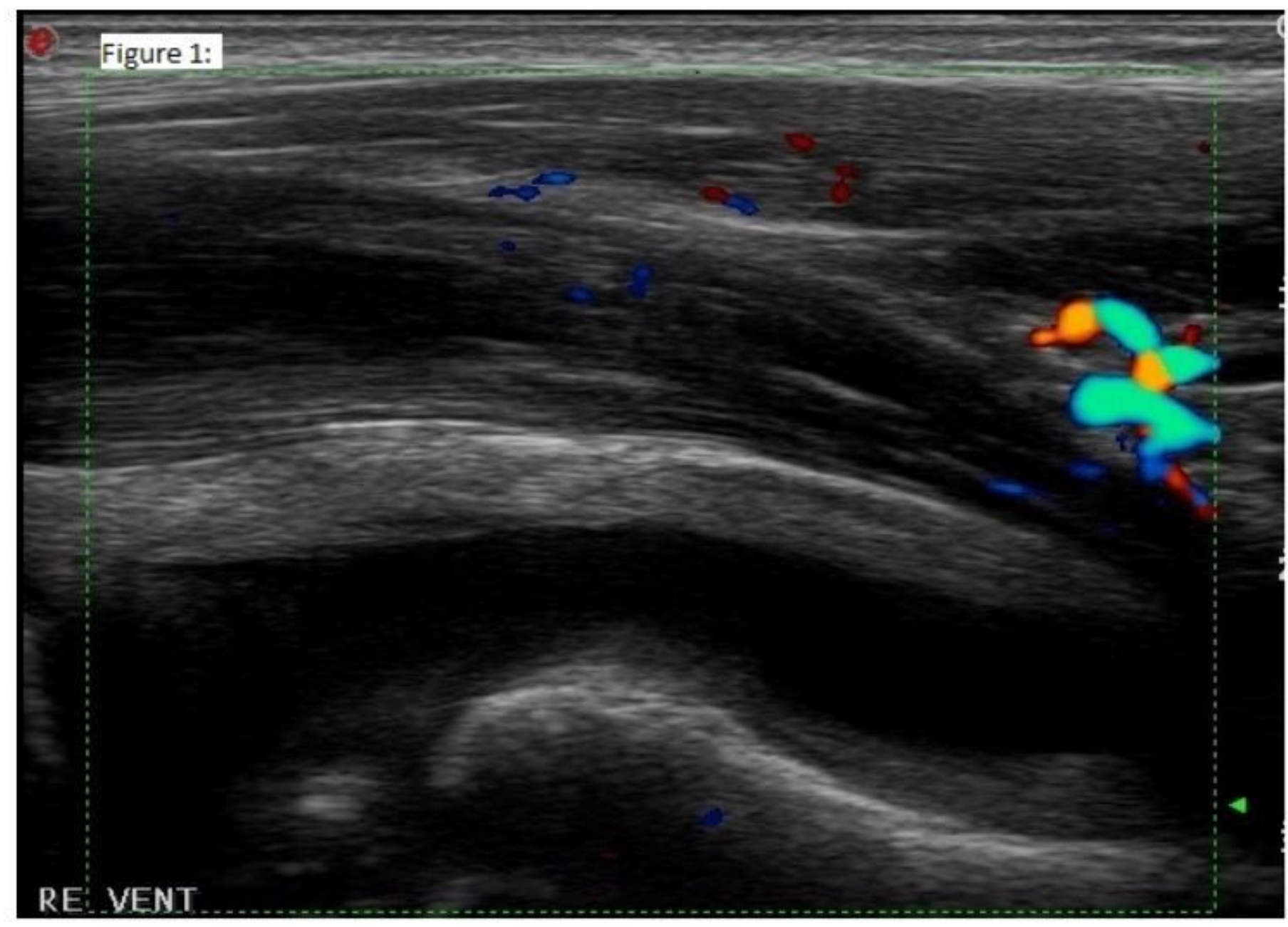

\section{Figure 1}

Right hip dorsomedian with significant effusion in May 05th 2020. 


\section{Figure 2:}

\section{Figure 2}

Right hip dorsomedian with no effusion in July 06th 2020. 